\title{
Use of a Standardized MxA Protein Measurement-Based Assay for Validation of Assays for the Assessment of Neutralizing Antibodies Against Interferon- $\beta$
}

\author{
Meenu Wadhwa, ${ }^{1}$ Meena Subramanyam, ${ }^{2}$ Susan Goelz,,${ }^{2,}$ Jaya Goyal, ${ }^{2}$ Vijay Jethwa, ${ }^{2, \dagger}$ \\ Wendy Jones, ${ }^{2,+}$ James G. Files, ${ }^{3, \S}$ Daniel Kramer, ${ }^{4}$ Chris Bird, ${ }^{1}$ Paula Dilger, \\ Michael Tovey, ${ }^{5}$ Christophe Lallemand, ${ }^{5}$ and Robin Thorpe
}

Effective monitoring of the development of neutralizing antibodies (NAbs) against IFN- $\beta$ in multiple sclerosis (MS) patients on IFN- $\beta$ therapy is important for clinical decision making and disease management. To date, antiviral assays have been the favored approach for NAb determination, but variations in assay conditions between laboratories and the increasing use of novel assays have contributed to the reporting of inconsistent antibody data between laboratories and between products. This study, undertaken at the request of the Committee for Medicinal Products for Human Use (CHMP) of the European Medicines Agency (EMA), is a joint effort by manufacturers of IFN- $\beta$ products (approved in Europe) towards harmonization of a NAb assay that facilitates generation of comparable NAb data, which, in conjunction with clinical outcomes, should prove useful for clinicians treating MS patients with IFN- $\beta$ products. This article describes the standardized cellular myxovirus resistance protein $\mathrm{A}(\mathrm{MxA})$ protein measurement-based assay for detection of IFN- $\beta$ NAbs and its use for the validation of assays used for the quantitative determination of such antibodies. Although titers varied between laboratories and the products used, utilization of IFN- $\beta 1$ a rather than IFN- $\beta 1 \mathrm{~b}$ as the challenge antigen produced more consistent results in the NAb assay. Adoption of the standardized assay improves comparability between laboratories circumventing problems that arise when different, nonstandardized assays are employed for immunogenicity assessment. Based on the data, the EMA recommended for standardization purposes, the use of IFN- $\beta 1 \mathrm{a}$ in NAb assays, independent of the therapeutic product used for therapy and validation of new $\mathrm{NAb}$ procedures against the standardized assay described.

\section{Introduction}

DVANCES IN MULTIPLE SCLEROSIs (MS) research have
led to an improved understanding of the disease and
availability of a number of disease-modifying therapies.
Among these is Interferon- $\beta$ (IFN- $\beta$ ), an immunomodulatory
protein that in clinical trials in relapsing remitting MS
(RRMS) patients has been shown to reduce relapses and di-
minish development of new inflammatory lesions as evi-
denced by magnetic resonance imaging (Jacobs and others
1996; PRISMS Study Group 1998; Goodin 2005; Clerico and
others 2007). In RRMS, therefore, IFN- $\beta$ products are widely used as first-line treatment. Defining a significant benefit in some MS patients, however, is very difficult, as MS is a complex, multi-faceted disease and patients continue to relapse, develop active lesions, or show increased disability despite treatment. The timely recognition of factors that affect the efficacy in individual patients is important, as such recognition could enable intervention and switching to other licensed therapeutics for effective management of disease.

Currently, 3 recombinant IFN- $\beta$ products-subcutaneous IFN- $\beta-1 \mathrm{~b}$ (Betaferon, Bayer, United Kingdom; also marketed as Extavia, Novartis, United Kingdom), intramuscular IFN- $\beta$-1a (Avonex, Biogen Idec, United Kingdom), and

\footnotetext{
${ }^{1}$ Biotherapeutics Group, National Institute for Biological Standards and Control, Hertfordshire, United Kingdom.

${ }^{2}$ Biogen Idec, Development Translational Medicine, Cambridge, Massachusetts.

${ }^{3}$ Berlex, Bayer Healthcare, Richmond, California.

${ }^{4}$ Merck KGaA, Institute of Drug Metabolism and Pharmacokinetics, Grafing, Germany.

${ }^{5}$ Laboratory of Biotechnology and Applied Pharmacology, Ecole Normale Supérieure de Cachan, Cachan Cedex, France.

${ }^{*}$ Current affiliation: Elan Pharmaceuticals, South San Francisco, California.

${ }^{\dagger}$ Current affiliation: Merck, Sharp \& Dohme, Durham, North Carolina.

Current affiliation: Aileron Therapeutics, Cambridge, Massachusetts.

${ }^{\S}$ Current affiliation: J. Files Consulting, San Rafael, California.
} 
subcutaneous IFN- $\beta$-1a (Rebif, Merck Serono, United Kingdom) - which vary in structure, formulation, dose, and route of administration are indicated in the EU for patients with relapsing MS or at high risk of developing MS after a single demyelinating event. None of the products are approved for patients with primary progressive MS (PPMS). While the IFN- $\beta-1 b$ product is an Escherichia coli expressed, nonglycosylated IFN- $\beta$, Met-1, Ser17 mutein (in which the cysteine residue at position 17 is replaced by a serine), both IFN$\beta$-1a products are glycosylated preparations (with an aminoacid sequence identical to the natural human protein) that are produced using Chinese hamster ovary $(\mathrm{CHO})$ cells (Karpusas and others 1998; Runkel and others 1998). Despite their differences, all products show clinical efficacy in RRMS, as they reduce the rate of relapses by $17 \%$ to $30 \%$ and new lesion activity by $65 \%$ to $88 \%$ and also slow the progression of physical disability and brain atrophy [Avonex FDA label; (Li and Paty 1999; Durelli and others 2002; Rudick and Goelz 2011)]. In trials in secondary progressive (SP)MS and PPMS, however, results have been inconsistent, largely due to differences in the characteristics of the patients treated (Rudick and Goelz 2011).

The effectiveness of IFN- $\beta$ in RRMS varies with a robust response and disease stabilization in some patients; while in others, the disease activity continues. A significant number of patients discontinue treatment either due to side effects or due to a perceived lack of efficacy with some patients developing antibodies against IFN- $\beta$ (Rio and others 2005).

The incidence and characteristics of the induced antibodies (eg, non-neutralizing or neutralizing) is variable and dependent on the administered IFN- $\beta$ product as well as on a host of other factors, including the dose, frequency, route of administration, patient status, and the method used for antibody detection.

It is now increasingly recognized that antibodies can have an impact on clinical outcome, although there is also evidence showing no discernible effect on clinical outcome despite an association of neutralizing antibody ( $\mathrm{Nab}$ ) positivity with increased brain lesions (Goodin and others 2012). Persistent IFN- $\beta$ NAbs ( $>2$ consecutive positive samples) are associated with reduced pharmacodynamics and loss of bioactivity (Bertolotto and others 2003; Scagnolari and others 2007; Deisenhammer 2009). A reduction in the clinical efficacy of IFN- $\beta$ as noted by an increased number of exacerbations and/or new lesions detected by MRI in NAb-positive (high titers) patients compared with those who were NAb negative is evident from some but not all clinical trials (Francis and others 2005; Kappos and others 2005; Goodin and others 2007; Pachner and others 2009). The unfavorable effect of the developed antibodies when noted appears to be independent of the type of IFN- $\beta$ used (Koch-Henriksen and others 2009).

Since IFN- $\beta$ products are intended for chronic use, the formation of NAbs is an important consideration affecting patient therapy and has aroused much debate. Based on accumulated evidence, expert panels have concluded that persistently high titers of NAbs $\left(>200 t_{1 / 10}\right)$ are likely to be associated with frequent relapses and exacerbation in disease (Goodin and others 2007; Polman and others 2010). Indeed, a recent study showed that high titers of NAbs, which persisted years after end of therapy, were associated with increased relapse rates and progressive disability. Switching patients from one IFN- $\beta$ product to another does not sig- nificantly change NAb titers, as induced antibodies crossreact with other IFN- $\beta$ products (Gneiss and others 2009). Importantly, effective monitoring of the development of NAbs using appropriate assay systems is crucial for clinical decision making and disease management (Polman and others 2010; Farrell and others 2011).

Establishing the exact magnitude of the clinical impact of NAbs on the efficacy of IFN- $\beta$ has been complicated due to the plethora of different assays used for determining NAbs, variable experimental conditions, differences in methods for calculating and defining NAb titers, and discrepancies in sampling times (Bertolotto 2009). Assays based on the inhibition of IFN activity using either antiviral (AVA) bioassays based on the cytopathic effect reduction (CPE) approach or, more recently, inhibition of an IFN-inducible gene, myxovirus resistance protein $\mathrm{A}(M x A)$, or secreted MxA protein are largely favored for monitoring and quantifying the levels of NAbs (Pungor and others 1998; Meager and Gaines-Das 2005; Mckay and others 2006; Bertolotto and others 2007; Goodin and others 2007). A number of reporter gene assays (RGA) have also been described (Lallemand and others 2008; Lam and others 2008). However, even among the AVA (the assay described in the European Pharmacopoeia for determination of biological activity of IFNs), comparisons have been difficult due to divergence in assay protocols with regard to cell-virus combinations, the amounts of virus, and the dose and type of IFN- $\beta$ used (Hartung and others 2007). This has resulted in a wide variation in the reporting of NAb frequencies and titers for the different products in various studies. For example, incidences of NAbs in patients treated with Avonex, Rebif, and Betaseron have been reported as $2 \%-6 \%, 12 \%-$ $28 \%$, and $28 \%-47 \%$, respectively (Bertolotto and others 2004; Deisenhammer 2009; Rudick and Goelz 2011) or as 13\% (Avonex), 30\%-39\% (Rebif), and 43\% (Betaseron) with each of the products separately (Sominanda and others 2007). However, the issue is further complicated, because in many of these assays, the correlation between titer level and assay signal to a clinically meaningful effect on the PK/PD or efficacy of the product has not been established and provides little useful information, if any, to the clinician in terms of disease management, emphasizing the need for well-standardized NAb assays (Goodin and others 2007).

This lack of standardization instigated the need for a common standardized NAb assay for facilitating a comparison for data generated across studies using different products so that a better understanding of the impact of NAbs on clinical outcome can be achieved. Consequently, the Committee for Medicinal Products for Human Use (CHMP) of the European Medicines Agency (EMA) requested the development of a standardized assay for measuring NAbs. Following this recommendation, the marketing authorization holders agreed to validate a common bioassay (EMA, 2008). The selection of an assay measures cytoplasmic accumulation of the IFN-inducible MxA protein, a $75 \mathrm{kD}$ cytoplasmic protein that is one of the markers of the biological activity of IFN- $\beta$ and is known to be applicable to the measurement of neutralizing IFN- $\beta$ NAbs (Towbin and others 1992; Files and others 1998; Pungor and others 1998). Moreover, it offered distinct advantages compared with the CPE assay, as it enabled easier standardization with possibility of automation, faster data turn-around time and eliminated the safety concerns associated with virus handling. 
Box 1. MxA Blind-Panel Study.

Study Coordinator: Huub Schellekens, Department of Pharmaceutical Sciences and Innovation Studies, Utrecht University, Sorbonnelaan 14-16, 3584 CA Utrecht, Netherlands.

Study Participants:

Biogen Idec, USA-Goelz S, Jones W, Goyal J, Jethwa V Berlex (now Bayer), USA-Files James G and others

Serono (now Merck Serono), Italy-Antonetti F and others

NIBSC for the planning, assembly and distribution of panels, data collation and statistical analysis.

This article describes the standardized cell-based assay for detection of IFN- $\beta$ NAbs based on results from a collaborative study in which a blind panel of serum samples $(n=62)$ was assessed for neutralizing activity by the 3 marketing authorization holders ("participants"-See Box 1) for IFN- $\beta$ products in the EU using a common IFN- $\beta$ preparation as the challenge antigen in all NAb assays. Data from assays in which each participant employed their own therapeutic IFN$\beta$ as the antigen is also shown. In addition, data derived for a set of samples $(n=11)$ by each participant using the 3 commercial IFN- $\beta$ products are also presented. The use of the MxA protein assay for validation of another representative $\mathrm{NAb}$ assay is also described.

\section{Materials and Methods}

\section{Materials}

Human fibroblast-derived IFN- $\beta$ (reference reagent $\mathrm{Gb}-$ 23-902-531, available from NIH, Bethesda, USA) and all approved IFN- $\beta$ products, Betaseron (IFN- $\beta 1 b$ ), Rebif (IFN$\beta 1 \mathrm{a})$, and Avonex (IFN- $\beta 1 \mathrm{a})$, obtained from their respective manufacturers, were used in the NAb assays. A human IFN$\beta$ NAb reference serum (G038-501-572; NIH) was used in validation studies. Serum test samples were obtained from NAb-positive MS patients undergoing therapy with 1 of 3 products-Betaseron, Avonex, or Rebif. Some samples were prepared as pools of similar titer sera (negative, low, medium, and high titer) from different patients who were being treated with the same therapeutic (Table 1). Some normal serum samples were isolated at the National Institute of Biological Standards and Control, NIBSC, United Kingdom. For the collaborative study, 62 serum samples from patients treated

Table 1. Blind-Panel Serum Samples Tested in the MxA Assay

\begin{tabular}{|c|c|c|c|c|c|c|c|c|c|}
\hline Sample & Origin (code) & $\begin{array}{l}\text { Previous } \\
\text { titer }\end{array}$ & $\begin{array}{c}\text { Selected } \\
\text { subset }\end{array}$ & Pos/Neg* & Sample & Origin (code) & $\begin{array}{l}\text { Previous } \\
\text { titer }\end{array}$ & $\begin{array}{c}\text { Selected } \\
\text { subset }\end{array}$ & Pos/Neg* \\
\hline 6 & $\mathrm{HC}$ & - & $S$ & - & 15 & Berlex (18) & 93 & & + \\
\hline 9 & M. Serono (2) & ND & & - & 12 & Berlex (21) & 63 & & + \\
\hline 16 & $\mathrm{HC}$ & - & & - & 33 & Berlex (26) & 22 & & + \\
\hline 29 & $\mathrm{HC}$ & - & & - & 8 & Berlex (28) & 49 & & + \\
\hline 38 & $\mathrm{HC}$ & - & & - & 11 & Biogen (5) & $50-200$ & & + \\
\hline 39 & $\mathrm{HC}$ & - & & - & 13 & Biogen (9) & $50-200$ & & + \\
\hline 43 & M. Serono (1) & ND & $S$ & - & 46 & Berlex (29) & 39 & & + \\
\hline 44 & $\mathrm{HC}$ & - & & - & 55 & Berlex (17) & 103 & & + \\
\hline 49 & $\mathrm{HC}$ & - & & - & 45 & M. Serono (4) & $10-50$ & S & + \\
\hline 50 & $\mathrm{HC}$ & - & & - & 59 & Biogen (1) & $>200$ & & + \\
\hline 60 & $\mathrm{HC}$ & - & & - & 48 & Berlex (23) & 64 & & + \\
\hline 61 & Other & 49 & $1: 100$ & + & 27 & Berlex $(19,22)$ & 75,72 & S & + \\
\hline 4 & Berlex (32) & $<10$ & & + & 36 & Berlex (12) & 253 & & + \\
\hline 52 & Other & + & $1: 50$ & + & 53 & Berlex (14) & 180 & & + \\
\hline 18 & M. Serono (1) & $10-50$ & & + & 10 & Berlex (16) & 113 & & + \\
\hline 19 & Other & + & $1: 25 S^{2}$ & + & 26 & Berlex (15) & 141 & & + \\
\hline 56 & Biogen (4) & $10-50$ & & + & 35 & Berlex (13) & 391 & & + \\
\hline 31 & Other & + & $1: 25 S^{2}$ & + & 28 & Berlex (11) & 250 & & + \\
\hline 54 & Biogen (8) & $10-50$ & & + & 5 & Berlex (10) & 389 & & + \\
\hline 47 & Biogen (7) & $10-50$ & & + & 1 & M. Serono (7) & $>200$ & & + \\
\hline 17 & Berlex (31) & 29 & & + & 25 & NIBSC (99/606) & $* * * * * * * *$ & & + \\
\hline 24 & Biogen (3) & $50-200$ & & + & 30 & Berlex (7) & 783 & & + \\
\hline 34 & Biogen (6) & $10-50$ & & + & 58 & M. Serono (8) & $>200$ & $\mathrm{~S}$ & + \\
\hline 20 & Other & 453 & $1: 10$ & + & 57 & Berlex (6) & 1366 & & + \\
\hline 37 & Berlex (30) & 21 & & + & 22 & Berlex (33) & $<10$ & & + \\
\hline 14 & M. Serono (5) & $50-200$ & S & + & 32 & Berlex (5) & 1574 & & + \\
\hline 7 & Berlex (27) & 32 & & + & 40 & Biogen (10) & $>200$ & & + \\
\hline 42 & Berlex (20) & 53 & & + & 23 & Berlex $(8,9)$ & 463,465 & S & + \\
\hline 41 & Berlex $(24,25)$ & 40,47 & S & + & 51 & Berlex $(3,4)$ & 2185, 2038 & $\mathrm{~S}$ & + \\
\hline 62 & M. Serono (6) & 50-200 & & + & 3 & Berlex (1) & 5409 & & + \\
\hline 2 & Biogen (2) & $>200$ & & + & 21 & Berlex (2) & 3051 & & + \\
\hline
\end{tabular}

$\mathrm{S}$ denotes selected samples, Other indicates patient sera obtained from another source; this was diluted as a dilution series for the study; sample at a 1:25 dilution was included as coded duplicates of the same sample $S^{2} ; \mathrm{HC}$, healthy control (untreated); ND, not detectable; ****** denotes not determined; M Serono, Merck Serono.

Sample codes, origin, previous titer (where available using in-house assays), and antibody status* as + for positive and - for negative confirmed by all participants in MxA assay using IFN- $\beta$ (NIH) as antigen in MxA assay is provided.

MxA, myxovirus resistance protein A. 
with each of the 3 products (sera sent by the manufacturers and a clinician to NIBSC, United Kingdom) and normal healthy sera were aliquotted, prepared as a blind panel (coded) at NIBSC, and distributed to the study participants.

\section{Participants}

Three participants [Biogen Idec; Merck-Serono; Berlex (now Bayer)] contributed NAb assay data for the blind-panel study.

\section{MxA protein NAb assay}

The NAb assay is a modification of the MxA induction assay for type I IFNs involving IFN- $\beta$ stimulation of the human A549 adenocarcinoma cell line previously described (Files and others 1998; Pungor and others 1998).

Briefly, serum samples were initially diluted 1:5 in assay medium containing $20 \mathrm{IU} / \mathrm{mL}$ of IFN- $\beta$ and serially diluted 2 -fold (to achieve up to a 1:1,280 dilution) in IFN- $\beta$ containing medium previously added into a 96-well plate. After $1 \mathrm{~h}$ at room temperature, $50 \mu \mathrm{L}$ of medium from each well was transferred, in duplicate, to wells of another 96-well sterile microtiter plate containing 5,000 A549 cells (ATCC CCL-185) in $50 \mu \mathrm{L}$ medium, seeded for $20-24 \mathrm{~h}$ earlier, and incubated at $37^{\circ} \mathrm{C}$. This provided a final concentration of $10 \mathrm{IU} / \mathrm{mL}$ IFN- $\beta$ and serum dilutions of 1:10-1:2560. After further incubation for $24 \mathrm{~h}$ at $37^{\circ} \mathrm{C}$, the media were aspirated gently, and the cells were lysed by addition of $100 \mu \mathrm{L}$ of lysis buffer $(25 \mathrm{mM}$ Tris-HCl-pH 7.2, $0.02 \%$ sodium azide, and $2 \%$ $\mathrm{NP}-40$ ) for approximately $2 \mathrm{~h}$ at room temperature. The lysates were frozen and assayed for accumulated cellular MxA protein using an ELISA.

MxA protein was determined using a rat anti-MxA monoclonal antibody (2D12; Biogen Idec) to capture and a biotinylated mouse anti-MxA monoclonal antibody (4E5; Biogen Idec) to detect the protein. Briefly, 96-well plates were immobilized with $100 \mu \mathrm{L}$ of capture antibody $(2 \mu \mathrm{g} / \mathrm{mL}$ in $0.2 \mathrm{M}$ sodium-carbonate-bicarbonate buffer, $\mathrm{pH}$ 9.4; Pierce Cat.no. 28382), stored overnight at $2^{\circ} \mathrm{C}-8^{\circ} \mathrm{C}$, washed (PBS containing $0.05 \%$ tween-20), and blocked (PBS with $3 \%$ BSA) for $1-2 \mathrm{~h}$ at room temperature or overnight at $2^{\circ} \mathrm{C}-8^{\circ} \mathrm{C}$. After a wash step, $50 \mu \mathrm{L}$ of samples (cell lysates, MxA-positive control cell lysate) and $50 \mu \mathrm{L}$ of the detector antibody $(0.5 \mu \mathrm{g} /$ $\mathrm{mL}$ in PBS with 3\% BSA) were added to the wells, and the plates were incubated overnight on a plate rotator at $2^{\circ} \mathrm{C}-$ $8^{\circ} \mathrm{C}$. Subsequent to washing, the wells were incubated with $100 \mu \mathrm{L}$ of streptavidin-HRP (1:10,000 dilution; Jackson ImmunoResearch Cat No., 016-030-084) for $30 \mathrm{~min}$, washed, and $100 \mu \mathrm{L}$ of TMB substrate peroxidase solution (BioFx, TMBW-001-01) was added. Color development was monitored, the reaction was stopped $\left(100 \mu \mathrm{L}\right.$ of $\left.1 \mathrm{~N} \mathrm{H}_{2} \mathrm{SO}_{4}\right)$, and the optical densities (OD) were measured in a microplate reader (Molecular Devices) at $450 \mathrm{~nm}$. The OD value is directly proportional to the concentration of MxA in each well.

A standard curve consisting of lysates from cells incubated with various concentrations of IFN- $\beta$ was included on each plate. The EC50 value from a 4-parameter curve fit of the IFN- $\beta$ standard curve was defined as 1 Lab Unit (LU) value for the assay. The sample titer was calculated using the Kawade formula (Kawade 1986): Reciprocal Dilution of Sample at Cutoff $\times[(10 / C$ value $)-1] / 9=$ titer; this defines the titer as the dilution of serum that reduces the amount of LU of IFN by $90 \%(1 \mathrm{LU}=\mathrm{EC} 50$ ie, 50\% MxA induction).

\section{Blind-panel study design}

Before assessing the blind-panel samples, the MxA NAb assay was validated by the 3 manufacturers and shown to have good reproducibility. All 3 participants were requested to assay all blind-panel samples $(n=62)$, shown in Table 1 , for neutralizing activity in the MxA NAb assay using a fibroblast-derived IFN- $\beta$ and their own therapeutic IFN- $\beta$ product as challenge antigens. A subset comprising 11 "selected samples" (codes 06, 14, 19, 23, 27, 31, 41, 43, 45, 51, 58), labeled S (Table 1), was included in the panel. This was tested by each participant using all 3 commercial IFN- $\beta$ products. Two samples coded 19 and 31 were included in the subset as duplicates (ie, identical except for sample code), to provide a direct measure of intra-assay variation, with which the observed inter-assay variation can be compared. Participants were requested to provide calculations of titer and raw assay data for all study samples.

\section{Participant data}

Each of the 3 participants provided a single titer value (based on their calculations) for each sample and antigen, although repeat assays and dilution curves with different starting dilutions were performed for some samples. Raw assay data provided included duplicate responses in adjacent columns of the plate for each preparation/dose. One participant also provided data from their in-house assay (data not included).

\section{Statistical analysis}

Analyses of titers were carried out at NIBSC after transformation of titers to log titers. Variation of estimates is summarized as the geometric coefficient of variation (GCV). The information for some variances is limited, in which case the associated degrees of freedom (df) are also given. Correlations were calculated for the log titers of the non-negative selected samples.

\section{Comparisons in independent laboratories}

Two laboratories carried out a further evaluation of the MxA protein NAb assay. The assay was performed using the same specified conditions and reagents (as described earlier) where possible. In comparative experiments, concentrations of antibody pairs for MxA ELISAs were different; the original antibodies (Biogen Idec) were used as indicated earlier, while the antibody pair (from Novartis and procured later) was used at a concentration of $4 \mu \mathrm{g} / \mathrm{mL}$. The latter antibodies at $4 \mu \mathrm{g} / \mathrm{mL}$ (for both) were also used in another laboratory for the cross-validation study in which the MxA assay, conducted using reagents available in house, was compared with a reporter gene NAb assay. The reporter gene NAb assay was carried out as previously described (Lallemand and others 2008) using assay-ready iLite cells obtained from Biomonitor Ltd.

\section{Results}

Before evaluation of blind-panel serum samples, the MxA $\mathrm{NAb}$ assay was assessed by the 3 companies for its suitability using a common validation protocol and assay design and found to demonstrate good reproducibility. The blind-panel 
study was conducted with an understanding that the description of the method and reagents for executing the MxA $\mathrm{NAb}$ assay is publicly available.

\section{Blind-panel study}

The complete blind panel $(n=62)$ was tested by each participant using fibroblast-derived IFN- $\beta$ and the participant's antigen in the assay. Therefore, the complete panel was tested only by a single participant for each of the 3 commercial preparations. Analysis of the data from the participants showed that there was 100\% consistency across the 3 laboratories, in terms of samples categorized "negative" for NAbs. All laboratories identified the negative samples included in the panel (Table 1) as negative irrespective of whether the fibroblast-derived IFN- $\beta$ (Table 2 ) or the manufacturer's unique antigen (Table 3) was used in the assay. On this basis, samples coded 06, 09, 16, 29, 38, 39, 43, 44, 49, 50 , and 60 were assigned titers of $<10$. Since all laboratories classified these samples as negative $(n=11)$, they have been omitted from a further analysis.

In terms of "non-negative" samples, all laboratories identified the remaining samples $(n=51)$ in the panel as positive for NAbs when using fibroblast-derived IFN- $\beta$ or the IFN- $\beta 1$ a antigen for challenge (Tables 2 and 3). For these preparations, therefore, a $100 \%$ concordance was observed between the different laboratories in terms of samples identified as "negative" and "positive" for NAbs. However, when IFN- $\beta 1 \mathrm{~b}$ product (Betaseron) was used as challenge antigen, 2 (code 04,56 ) of the 51 samples tested did not show quantifiable neutralization, resulting in 3\% disconcordance between the different laboratories in terms of samples identified as "negative" and "positive" for NAbs. The neutralization titers, derived by each of the participants, using either fibroblast-derived IFN- $\beta$ or their own IFN- $\beta$ product as the challenge antigen in the MxA assay, are shown in Tables 2 and 3 , respectively. The 2 discordant samples, coded 04 and 56 , were of low titer but showed some neutralizing activity

Table 2. Neutralization Titers Obtained by the 3 Participants Using Fibroblast-Derived IFN- $\beta$ (2ND IS, NIH) As Challenge Antigen in the MxA Assay

\begin{tabular}{|c|c|c|c|c|c|c|c|}
\hline Sample & Biogen Idec/1 & Merck Serono/2 & Berlex $/ 3$ & Sample & Biogen Idec/1 & Merck Serono/2 & Berlex $/ 3$ \\
\hline 6 & $<10$ & $<10$ & $<10$ & 15 & 326 & 350 & 279 \\
\hline 9 & $<10$ & $<10$ & $<10$ & 12 & 350 & 318 & 321 \\
\hline 16 & $<10$ & $<10$ & $<10$ & 33 & 370 & 357 & 486 \\
\hline 29 & $<10$ & $<10$ & $<10$ & 8 & 394 & 391 & 344 \\
\hline 38 & $<10$ & $<10$ & $<10$ & 11 & 412 & 394 & 423 \\
\hline 39 & $<10$ & $<10$ & $<10$ & 13 & 421 & 418 & 348 \\
\hline 43 & $<10$ & $<10$ & $<10$ & 46 & 426 & 379 & 329 \\
\hline 44 & $<10$ & $<10$ & $<10$ & 55 & 442 & 385 & 364 \\
\hline 49 & $<10$ & $<10$ & $<10$ & 45 & 553 & 467 & 425 \\
\hline 50 & $<10$ & $<10$ & $<10$ & 59 & 747 & 725 & 697 \\
\hline 60 & $<10$ & $<10$ & $<10$ & 48 & 784 & 849 & 814 \\
\hline 61 & 24 & 29 & 27 & 27 & 798 & 595 & 582 \\
\hline 4 & 37 & 30 & 46 & 36 & 824 & 678 & 898 \\
\hline 52 & 48 & 42 & 50 & 53 & 951 & 780 & 586 \\
\hline 18 & 79 & 64 & 57 & 10 & 1439 & 1198 & 1293 \\
\hline 19 & 99 & 98 & 76 & 26 & 1711 & 968 & 982 \\
\hline 56 & 102 & 73 & 77 & 35 & 2001 & 2080 & 1388 \\
\hline 31 & 116 & 107 & 80 & 28 & 2118 & 1450 & 1196 \\
\hline 54 & 145 & 100 & 118 & 5 & 2125 & 1580 & 1081 \\
\hline 47 & 171 & 111 & 158 & 1 & 2401 & 2195 & 1625 \\
\hline 17 & 179 & 108 & 89 & 25 & 2457 & 1200 & 1508 \\
\hline 24 & 195 & 260 & 162 & 30 & 4098 & 2188 & 2151 \\
\hline 34 & 212 & 162 & 247 & 58 & 4845 & 5545 & 3019 \\
\hline 20 & 223 & 164 & 183 & 57 & 5009 & 3331 & 2722 \\
\hline 37 & 228 & 161 & 173 & 22 & 5115 & 2420 & 2289 \\
\hline 14 & 270 & 157 & 180 & 32 & 5166 & 3309 & 2956 \\
\hline 7 & 271 & 174 & 161 & 40 & 10818 & 9329 & 10604 \\
\hline 42 & 292 & 208 & 228 & 23 & 13973 & 12598 & 10082 \\
\hline 41 & 294 & 235 & 224 & 51 & 24606 & 22487 & 13370 \\
\hline 62 & 298 & 252 & 291 & 3 & 25348 & 25100 & 17333 \\
\hline 2 & 301 & 265 & 291 & 21 & 30624 & 22269 & 23439 \\
\hline
\end{tabular}

$<10=$ neg.

$10-100=$ low.

$100-1000=$ mid.

$>1000=$ high . 
Table 3. Neutralization Titers Obtained by the 3 Participants Using Their Own IFN- $\beta$ Product as Challenge Antigen in the MxA Assay

\begin{tabular}{|c|c|c|c|c|c|c|c|}
\hline Sample & Avonex & Rebif & Betaferon & Sample & Avonex & Rebif & Betaferon \\
\hline 6 & $<10$ & $<10$ & $<10$ & 15 & 534 & 284 & 110 \\
\hline 9 & $<10$ & $<10$ & $<10$ & 12 & 461 & 321 & 75 \\
\hline 16 & $<10$ & $<10$ & $<10$ & 33 & 623 & 342 & 86 \\
\hline 29 & $<10$ & $<10$ & $<10$ & 8 & 538 & 304 & 70 \\
\hline 38 & $<10$ & $<10$ & $<10$ & 11 & 473 & 324 & 91 \\
\hline 39 & $<10$ & $<10$ & $<10$ & 13 & 707 & 555 & 89 \\
\hline 43 & $<10$ & $<10$ & $<10$ & 46 & 815 & 400 & 63 \\
\hline 44 & $<10$ & $<10$ & $<10$ & 55 & 773 & 309 & 129 \\
\hline 49 & $<10$ & $<10$ & $<10$ & 45 & 828 & 337 & 79 \\
\hline 50 & $<10$ & $<10$ & $<10$ & 59 & 1189 & 622 & 84 \\
\hline 60 & $<10$ & $<10$ & $<10$ & 48 & 1009 & 693 & 170 \\
\hline 61 & 46 & 19 & 13 & 27 & 924 & 609 & 129 \\
\hline 4 & 83 & 31 & $<10^{*}$ & 36 & 2448 & 970 & 489 \\
\hline 52 & 100 & 52 & 14 & 53 & 1318 & 827 & 301 \\
\hline 18 & 110 & 38 & 18 & 10 & 866 & 734 & 199 \\
\hline 19 & 208 & 104 & 25 & 26 & 1731 & 868 & 371 \\
\hline 56 & 172 & 71 & $<10^{*}$ & 35 & 2731 & 1740 & 507 \\
\hline 31 & 214 & 108 & 39 & 28 & 3174 & 1395 & 461 \\
\hline 54 & 165 & 92 & 23 & 5 & 2452 & 1640 & 235 \\
\hline 47 & 184 & 134 & 27 & 1 & 3802 & 2342 & 394 \\
\hline 17 & 464 & 200 & 64 & 25 & 3505 & 1604 & 947 \\
\hline 24 & 305 & 154 & 21 & 30 & 7504 & 3341 & 779 \\
\hline 34 & 288 & 153 & 41 & 58 & 6754 & 4274 & 1029 \\
\hline 20 & 392 & 328 & 89 & 57 & 7212 & 2476 & 1105 \\
\hline 37 & 307 & 149 & 39 & 22 & 3473 & 1824 & 292 \\
\hline 14 & 445 & 182 & 45 & 32 & 6447 & 2264 & 1035 \\
\hline 7 & 312 & 144 & 27 & 40 & 14249 & 9434 & 1595 \\
\hline 42 & 507 & 243 & 54 & 23 & 14426 & 15100 & 2698 \\
\hline 41 & 476 & 282 & 47 & 51 & 33382 & 26800 & 5032 \\
\hline 62 & 416 & 212 & 37 & 3 & 44893 & 44100 & 8071 \\
\hline 2 & 525 & 324 & 37 & 21 & 46248 & 30016 & 6854 \\
\hline
\end{tabular}

$<10=$ neg.

$10-100=$ low.

$100-1000=$ mid.

$>1000=$ high .

*Neutralization below limit of quantitation when Betaferon is used as challenge antigen (see results section).

when either of the IFN- $\beta 1$ a products, Avonex or Rebif, were used. In particular, sample 56 showed moderate neutralization with both products. However, when tested using Betaseron, although the samples exhibited detectable neutralization, the titer values were below the lowest dilution and limit of quantitation $(1: 10)$ - these are shown by $<10^{*}$ in Table 3.

An examination of correlation coefficients for the 51 nonnegative samples indicated a complex relationship. Correlation coefficients for values obtained with the common assay using the fibroblast-derived IFN- $\beta$ in the different laboratories were $\geq 0.99$. Correlations among the values obtained using the fibroblast-derived IFN- $\beta$ and the 2 IFN- $\beta 1$ a products, Avonex and Rebif, were $\geq 0.98$. Correlations of values obtained using the IFN- $\beta 1$ b product, Betaseron with those obtained using fibroblast-derived IFN- $\beta$, Rebif, or Avonex were $\geq 0.96$.

\section{Selected samples}

Among the subset of 11 "selected samples" (codes 06, 14, $19,23,27,31,41,43,45,51,58)$ tested by each participant using all 3 commercial IFN- $\beta$ products, samples coded 06 and 43 were found to be negative and were, therefore, excluded from a further analysis. The reported titers for the 9 non-negative samples, including the 2 identical (which provide a direct measure of intra-assay variation, with which the observed inter-assay variation can be compared) samples coded 19 and 31, are shown in Table 4. For any preparation/ laboratory, the correlation coefficient for these 9 samples was greater than 0.98 .

The intra-assay variation was pooled over laboratories for each preparation (3 df for each preparation) and also within each laboratory over the 4 preparations ( $4 \mathrm{df}$ for each laboratory). The associated GCVs for the commercial 
Table 4. Neutralization Titers for the Subset of Selected (9 Non-Negative) Samples Using 4 Different IFN- $\beta$ Preparations for Neutralization in the MxA Assay

\begin{tabular}{|c|c|c|c|c|c|c|c|c|c|c|c|c|}
\hline \multirow[b]{2}{*}{ Sample } & \multicolumn{3}{|c|}{ Biogen Idec } & \multirow{2}{*}{$\begin{array}{c}\text { Fibroblast- } \\
\text { derived }\end{array}$} & \multicolumn{3}{|c|}{ Berlex } & \multirow{2}{*}{$\begin{array}{c}\text { Fibroblast- } \\
\text { derived }\end{array}$} & \multicolumn{3}{|c|}{ Merck Serono } & \multirow{2}{*}{$\begin{array}{c}\text { Fibroblast- } \\
\text { derived }\end{array}$} \\
\hline & Avonex & Betaseron & Rebif & & Avonex & Betaseron & Rebif & & Avonex & Betaseron & Rebif & \\
\hline 14 & 445 & 66 & 287 & 270 & 283 & 45 & 255 & 180 & 224 & 57 & 182 & 157 \\
\hline 23 & 14426 & 6388 & 13392 & 13973 & 11778 & 2699 & 19770 & 10082 & 15337 & 4269 & 15100 & 2598 \\
\hline 27 & 924 & 193 & 579 & 798 & 564 & 129 & 699 & 582 & 658 & 127 & 609 & 595 \\
\hline 41 & 476 & 82 & 268 & 294 & 263 & 47 & 297 & 224 & 361 & 62 & 282 & 235 \\
\hline 45 & 828 & 190 & 423 & 553 & 479 & 79 & 599 & 425 & 429 & 161 & 337 & 467 \\
\hline 51 & 33382 & 14775 & 25621 & 24606 & 25842 & 5032 & 38838 & 13370 & 27613 & 8948 & 26800 & 22487 \\
\hline 58 & 6754 & 1314 & 4040 & 4845 & 4234 & 1030 & 6223 & 3019 & 4344 & 1300 & 4274 & 5545 \\
\hline $19^{*}$ & 208 & 61 & 154 & 99 & 144 & 25 & 157 & 76 & 102 & 48 & 104 & 98 \\
\hline $31^{*}$ & 214 & 55 & 142 & 116 & 119 & 39 & 149 & 80 & 101 & 49 & 108 & 107 \\
\hline
\end{tabular}

preparations, Avonex, Betaseron, and Rebif are $8 \%, 20 \%$, and $4 \%$ respectively. For the fibroblast-derived preparation, the GCV was $8 \%$. The GCV for participating laboratories was $18 \%$ (Berlex), 8\% (Biogen), and 4\% (Serono), respectively. Although these data are limited for drawing any reliable conclusions, it is consistent with dependence of the variance on both the laboratory and the preparation.

Comparisons of the between-laboratory variation with the within-laboratory variation for the coded duplicates using each preparation showed that the between-laboratory variation was significantly larger than the within-laboratory within assay variation (the reported titers do not provide replicate assays for these samples, and, hence, no estimate of the between assay within laboratory variation is available). The difference was significant for Avonex and Rebif $(P<0.01)$, and marginally significant for the fibroblast-derived $(P=\sim 0.05)$ and Betaseron $(P=\sim 0.10)$ preparations.

\section{Inter-laboratory variation}

The inter-laboratory variation has been determined for the common assay with each preparation, pooled across all samples. For the commercial preparations, 9 non-negative samples were analyzed in all laboratories, and for the fibroblast-derived IFN- $\beta$ preparation, 51 non-negative samples were analyzed in all laboratories. The GCVs were $34 \%$, $42 \%, 23 \%$, and $25 \%$ for Avonex, Betaseron, Rebif, and fi- broblast-derived IFN- $\beta$, respectively. These data suggest that the inter-laboratory variation for Betaseron may be larger than that for the other preparations, and that for Avonex, it may be slightly larger than that for Rebif and fibroblast-derived IFN- $\beta$.

The inter-laboratory variance of the reported titers for all samples using the common fibroblast-derived IFN- $\beta$ preparation gave a GCV of $24 \%$ compared with GCV of $189 \%$ for the reported titers when each laboratory used the individual antigen. For the selected samples, the GCVs using any one of the preparations as the "common antigen" were found to be 34\% (Avonex), 42\% (Betaseron), and 23\% (Rebif).

Analysis of variance of the log titers for each antigen shows that there are highly significant differences between laboratories, $P<0.001$ for each preparation. This is consistent with the findings for the coded duplicate samples, where the limited number of observations limited the ability to detect clearly the significant differences between laboratories.

\section{Ranks of titers}

The close agreement among estimates is also shown by the consistency with which the subset of 11 selected samples is ranked (Table 5). The ranks of the coded duplicate samples are of interest. Considering only the 9 non-negative samples, the duplicates have ranks of either 1 or 2 . For the 3 commercial preparations, either ranking appears to be equally likely; whereas for the fibroblast-derived IFN- $\beta$ preparation,

Table 5. Ranking for the Subset of Selected (9 Non-Negative) Samples Using 4 Different IFN- $\beta$ Preparations for Neutralization in the MxA Assay

\begin{tabular}{|c|c|c|c|c|c|c|c|c|c|c|c|c|}
\hline \multirow[b]{2}{*}{ Sample } & \multicolumn{3}{|c|}{ Biogen } & \multirow{2}{*}{$\begin{array}{c}\text { Fibroblast- } \\
\text { derived }\end{array}$} & \multicolumn{3}{|c|}{ Berlex } & \multirow{2}{*}{$\begin{array}{c}\text { Fibroblast- } \\
\text { derived }\end{array}$} & \multicolumn{3}{|c|}{ Merck Serono } & \multirow{2}{*}{$\begin{array}{c}\text { Fibroblast- } \\
\text { derived }\end{array}$} \\
\hline & Avonex & Betaseron & Rebif & & Avonex & Betaseron & Rebif & & Avonex & Betaseron & Rebif & \\
\hline 14 & 3 & 3 & 4 & 3 & 4 & 3 & 3 & 3 & 3 & 3 & 3 & 3 \\
\hline 23 & 8 & 8 & 8 & 8 & 8 & 8 & 8 & 8 & 8 & 8 & 8 & 8 \\
\hline 27 & 6 & 6 & 6 & 6 & 6 & 6 & 6 & 6 & 6 & 5 & 6 & 6 \\
\hline 41 & 4 & 4 & 3 & 4 & 3 & 4 & 4 & 4 & 4 & 4 & 4 & 4 \\
\hline 45 & 5 & 5 & 5 & 5 & 5 & 5 & 5 & 5 & 5 & 6 & 5 & 5 \\
\hline 51 & 9 & 9 & 9 & 9 & 9 & 9 & 9 & 9 & 9 & 9 & 9 & 9 \\
\hline 58 & 7 & 7 & 7 & 7 & 7 & 7 & 7 & 7 & 7 & 7 & 7 & 7 \\
\hline $19^{*}$ & 1 & 2 & 2 & 1 & 2 & 1 & 2 & 1 & 2 & 1 & 1 & 1 \\
\hline $31^{*}$ & 2 & 1 & 1 & 2 & 1 & 2 & 1 & 2 & 1 & 2 & 2 & 2 \\
\hline
\end{tabular}

*denotes coded duplicates. 


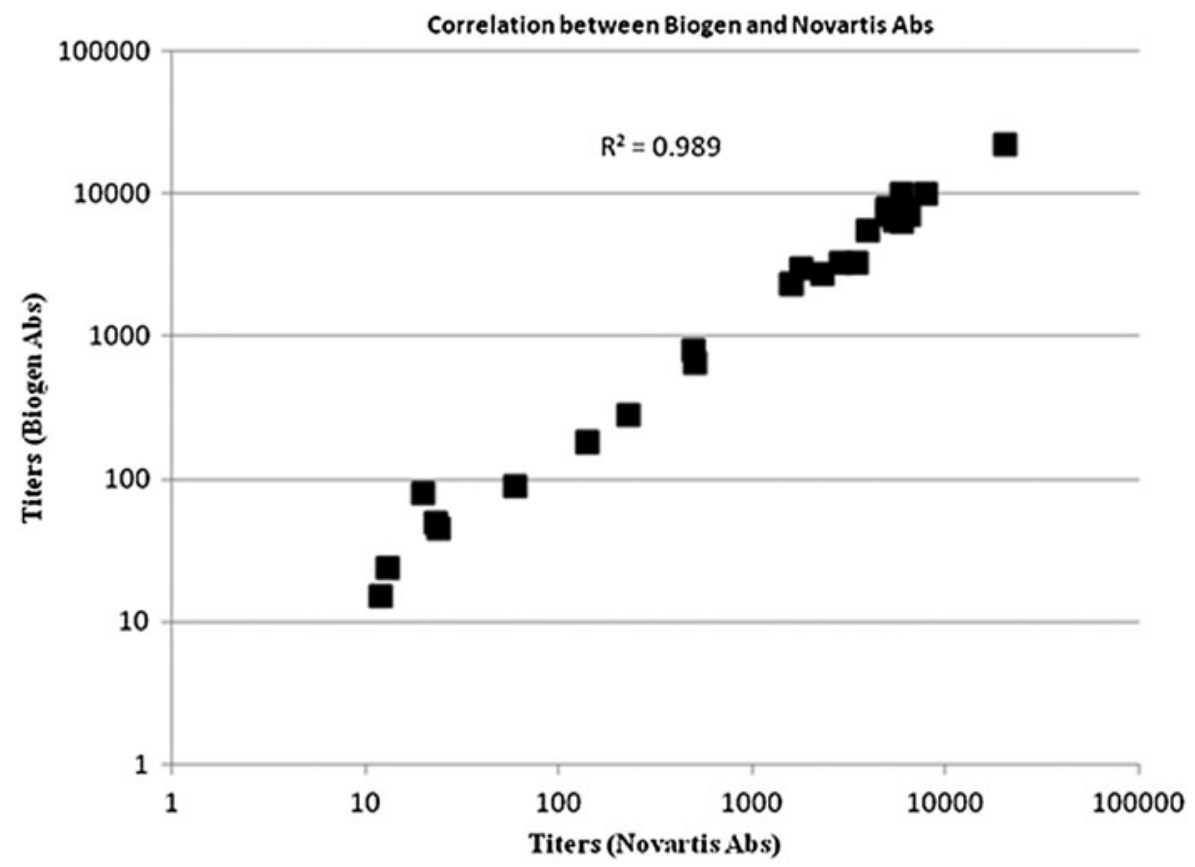

FIG. 1. IFN- $\beta$ NAb titers in antibody-positive patient sera using different antibody pairs in MxA ELISA for determination of MxA protein. IFN- $\beta 1$ a was used as the challenge antigen in the MxA assay; using Pearson's correlation, $\mathrm{r}=0.994 \quad(n=28$ for antibody-positive samples; $n=31$ in total). MxA, myxovirus resistance protein $\mathrm{A}_{i}$ Nab, neutralizing antibody.

sample 19 consistently has rank 1 and sample 31 has rank 2 . For samples 14 and 41, the titers are also not significantly different, resulting in a consistent ranking of either 3 or 4 . When all 51 samples are considered, the ranking order is 5, 5, and 6 for sample 19 or 7; 7, 8 for sample 31 when fibroblastderived IFN- $\beta$ is used by Berlex, Biogen, and Merck Serono, respectively (data not shown).

\section{Further studies}

MxA monoclonal antibodies produced by Biogen Idec were used in the blind-panel study. Antibodies derived from hybridomas provided by Novartis (Towbin and others 1992) were compared with the original antibody pair (Biogen Idec) for their suitability to detect MxA protein in the MxA NAb assay. Serum samples from MS patients were evaluated using the common assay protocol described, and the MxA protein was detected by ELISA using either the original (coating and detector) antibody pair or the newly obtained antibody pair (mAb 32 for capture; mAb 16 for detection) and the antibody titers were estimated. Similar results were obtained for all samples using either of the antibody pairs for the MxA ELISA. Antibody-negative samples were negative in both assay systems, and all antibody-positive samples were positive in both assay systems. While NAb titers derived from both assays are broadly consistent, it was noted that titer values for antibody-positive samples were generally higher when using the original antibody pair in comparison with the substituted antibody pair. Despite this, titers derived from each assay were highly correlated, $\mathrm{r}=0.994(n=28)$ as indicated in Fig. 1 .

\section{Comparative validation study using the standardized assay by an independent laboratory}

A part of the aims of the project to develop a standardized assay for measuring IFN- $\beta$ NAbs was that the description of the assay and critical reagents for carrying it out are publicly available. Although it was clear from the study described earlier that all 3 manufacturers of IFN- $\beta$ products could successfully carry out the assay, it had not been established that it could be transferred to another laboratory for crossvalidation of an in-house method. It was, therefore, decided to provide a brief description of the assay method and the $\mathrm{mAbs}$ for carrying out the ELISA for measuring MxA protein to an independent laboratory to establish that the assay could be used for cross-validation purposes.

For this, data derived using the standardized assay for assaying a number of serum samples containing different amounts and types of IFN- $\beta$ NAbs were compared with data derived using an RGA (Lallemand and others 2008) for measuring IFN- $\beta$ NAbs for the same samples in the same independent laboratory.

Results from this study clearly showed that the standardized assay was fit for purpose, as results derived using either assay method were essentially comparable (Fig. 2). An assessment of NAb titers for the antibody-positive patient samples using IFN - $\beta 1 \mathrm{a}$ and IFN- $\beta 1 \mathrm{~b}$ as the challenge antigen gave Pearson's correlation coefficient, $r=0.951$ and $\mathrm{r}=0.906$ respectively, Therefore, a good correlation was noted between the MxA protein assay and the RGA used in the study.

\section{Discussion}

MS is a chronic inflammatory autoimmune disease causing demyelination and formation of lesions in the central nervous system, often with progression of disability over time. It affects $\sim 2.5$ million people worldwide (100-150 per 100,000 people in UK) and comprises several disease subtypes. In a majority of patients (85\%), the onset of MS begins with a clinically isolated syndrome (CIS), which usually leads to the relapsing-remitting form, RRMS. RRMS is initially characterized by acute exacerbations (or relapses) of neurological dysfunction followed by periods of remissions and further progresses to the SPMS associated with functional impairment and increased morbidity and mortality. A minority of patients $(\sim 15 \%)$ begin with PPMS with disease 

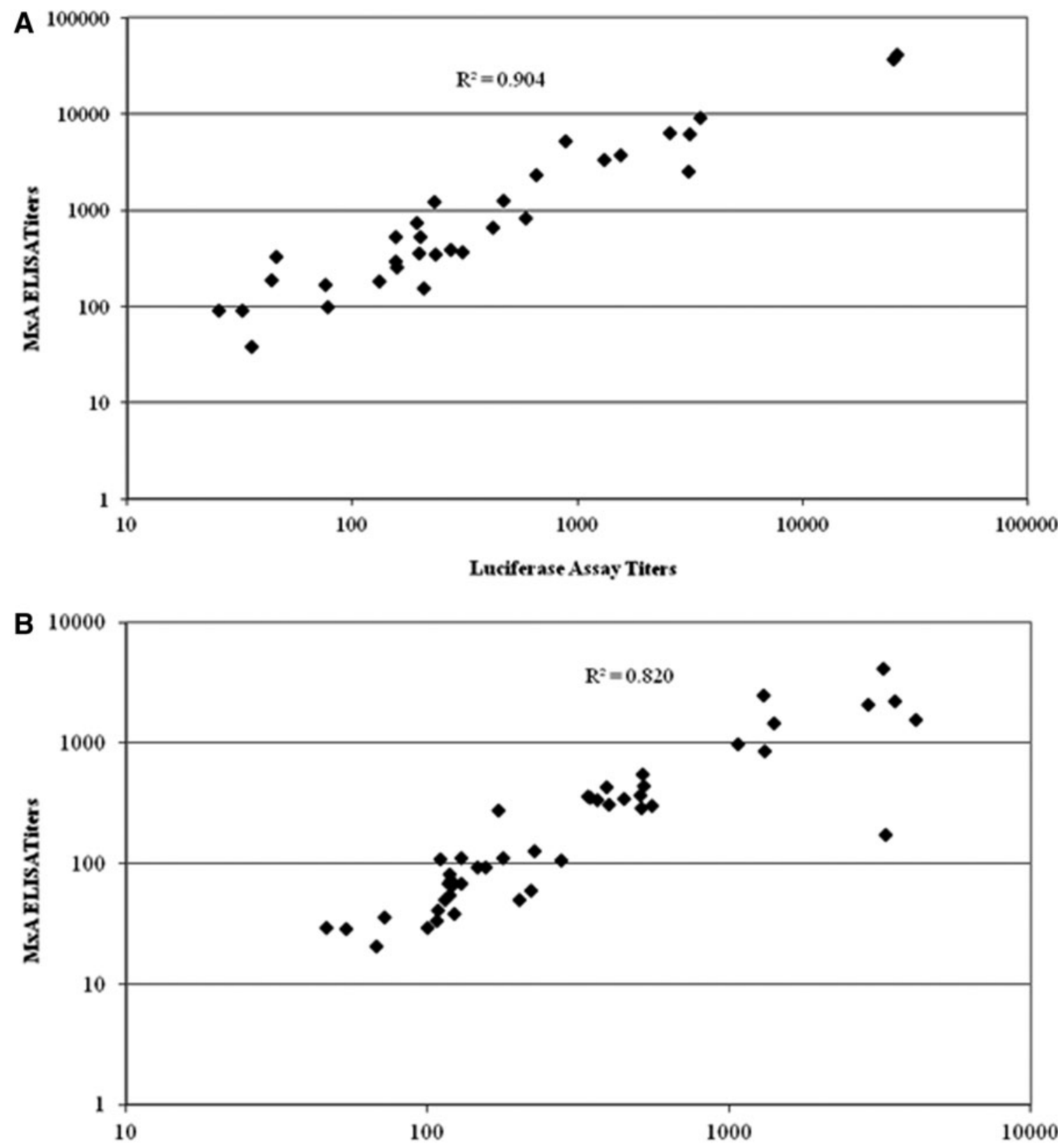

Luciferase Assay Titers

FIG. 2. IFN- $\beta$ NAb titers for antibody-positive patient sera using the MxA and luciferase NAb assays. (A) Using IFN- $\beta 1 a$ as the challenge antigen ( $n=52$ in total), the Pearson's correlation, $\mathrm{r}=0.951$ for the antibody-positive samples $(n=32)$. (B) Using IFN- $\beta 1 \mathrm{~b}$ as the challenge antigen $(n=65$ in total), the Pearson's correlation, $r=0.906$ for the antibody-positive samples $(n=45)$.

progression from onset, or progressive relapsing MS characterized by disease progression from onset but with superimposed acute relapses, with or without recovery (Lublin and Reingold 1996).

Despite promising results for newer therapies such as monoclonal antibodies (eg, natalizumab) and oral agents (eg, fingolimod), the favorable safety profile of IFN- $\beta$ indicates that its use in RRMS as one of the first-line treatment options is likely to continue (Killestein and others 2011). Some neurologists also advocate its use at the CIS stage, as this represents the first opportunity that may be beneficial in the long term (Farrell and Giovannoni 2010; Comi and others 2012; Giovannoni 2012). Evidence suggests that IFN- $\beta$ acts at various levels for example, by inhibiting MHC class II expression and the recognition between antigen-presenting cells and T cells, reducing T-cell activation and proliferation, inhibiting development and activation of TH17 cells, inducing regulatory $\mathrm{T}$ cells, and modulating cytokine production toward an anti-inflammatory profile (Dhib-Jalbut and Marks 2010).

IFN- $\beta$ treatment is, however, associated with antibody formation, which reduces the beneficial aspects of therapy. Testing for antibodies is imperative for disease management of these patients. Consistent with the systematic evaluation of immunogenicity advocated by regulatory authorities (EMA 2007), the spectrum of available cell-based assays for 
IFNs should provide the means to accurately measure NAbs to IFNs. Until recently, the measurement of NAbs with a validated CPE assay was considered the gold standard for assessment of NAbs in patient sera. Published guidelines recommended an NAb test performed in specialized laboratories using a validated bioassay employing A549 cells challenged with EMC virus for measuring CPE activity using a fixed amount of IFN- $\beta$ for stimulation and serial dilutions of sera. However, other cell-virus combinations and novel approaches are increasingly being used. The broad choice of available assays and inharmonious methods of analysis have led to disparities in reported NAb incidence, titers, and controversies regarding clinical relevance of Nabs, emphasizing the need for a standardized approach for NAb determination.

A reference assay that uses the same reagents, format, and conditions was, therefore, considered by the EMA as a means of producing harmonious results between different laboratories. Consequently, at the request of the Biologics Working Party (BWP) of the EMA's CHMP, NIBSC coordinated a collaborative study among the manufacturers of IFN- $\beta$ products in which a blinded panel of serum samples with variable titers (previously determined to be negative, high, medium, and low) from RRMS patients was assessed for NAbs using a common "reference assay" based on NAb inhibition of IFN- $\beta$-induced MxA protein in the A549 human lung carcinoma cell line (Files and others 1998; Pungor and others 1998). All 3 study participants used the same cell line, experimental conditions, and reagents for the assay to minimize the reagent/procedure-related variance. The constant IFN method was applied, and the assay was performed using first, human fibroblast-derived IFN- $\beta$ and second, each participants' own commercial IFN- $\beta$ product. The assay was designed such that the results could be reported as the reciprocal dilution of serum required for the reduction of 10 to $1 \mathrm{LU} / \mathrm{mL}$, following the procedure of Kawade (Kawade 1986; Grossberg and others 2001a, 2001b).

An analysis of the collaborative study data involving a cohort of 62 samples showed there was 100\% consistency across the 3 laboratories, in terms of samples that were "negative" for NAbs irrespective of the antigen (fibroblast-derived IFN- $\beta$ or the manufacturer's antigen) used in the assay.

For the other "non-negative" samples, all laboratories identified them as positive for NAbs when using either fibroblast-derived IFN- $\beta$ (NIH, 2nd IS) or IFN- $\beta 1$ a antigen for challenge. For these preparations, therefore, a 100\% concordance was observed between the different laboratories for samples identified as "negative" and "positive" for NAbs. However, when an IFN- $\beta 1 \mathrm{~b}$ product (Betaseron) was used as challenge antigen, 2 samples (which were of low titer when using any of the IFN- $\beta 1$ a products) did not show quantifiable neutralization, resulting in 3\% disconcordance between the different laboratories in terms of samples identified as "negative" and "positive" for NAbs. For all non-negative samples, titers obtained against IFN- $\beta-1 b$ were consistently lower than those obtained against the 2 IFN- $\beta-1$ a products. In addition, reported titers in Table 1 using in-house (nonstandard) assays were generally lower than those seen with MxA assay. Original cohorts were low titer $=10-50$, mid titer $=50-200$, high titer $>200$ and negative samples $<10$ but the titers from the MxA assay are higher due to the improved sensitivity of the assay. This means that there is a need to reestablish clinically relevant titers with the MxA assay.
Statistical analysis of the data showed that the intra-assay variation based on coded duplicates was low but the magnitude may be dependent on the laboratory and/or antigen. However, the inter-laboratory variation in reported titers was significantly larger than within-assay variation for the duplicate samples. The magnitude of the inter-laboratory variation was larger for IFN- $\beta-1 b$ than for the other antigens. However, when a common antigen was used in the different laboratories as opposed to a different antigen in each laboratory, the inter-laboratory variation was reduced. Correlation coefficients showed that the agreement between estimates for the samples is more consistent when a common antigen (rather than different antigens) is used in the different laboratories. Estimates were more consistent when fibroblast-derived IFN- $\beta$ or either of the 2 IFN- $\beta 1$ a antigens was used as opposed to IFN- $\beta-1 b$. In accordance with this, the neutralization titers were highly concordant when fibroblast-derived IFN- $\beta$ or the 2 IFN- $\beta 1$ a products were used as the challenge antigens but often lower when tested against the IFN- $\beta-1 b$ antigen regardless of whether the serum sample was obtained from patients treated with IFN- $\beta 1$ a or IFN- $\beta 1 b$. The reason for the variation in titers between IFN- $\beta 1 \mathrm{a}$ and IFN- $\beta 1 \mathrm{~b}$ is not fully understood, although several reasons have been postulated including differences in specific activity, protein folding, glycosylation, and degree of aggregation (Runkel and others 1998; Files and others 2007; van Beers and others 2010).

On the basis of these results, it was concluded that the standardized MxA NAb assay is a suitable assay for detection of NAbs against IFN- $\beta$. However, based on the limited supply of the natural IFN- $\beta$ (fibroblast-derived, 2 nd IS) standard, its use as a challenge antigen for routine testing was not appropriate. Since statistical analysis undertaken showed high concordance in results when using the IFN- $\beta 1$ a antigen ( $\mathrm{CHO}$ derived), the BWP (EMA CHMP) recommended the use of IFN- $\beta 1$ a antigen as the challenge antigen for the MxA assay as well as the CPE assay. In further studies, evaluation of 2 different MxA antibody pairs generated essentially similar results, showing that either antibody pair can be used for the common assay.

More recently, several novel assays, including RGA, have been described for measuring NAbs (Lallemand and others 2008; Lam and others 2008). An RGA assay has also been incorporated in routine clinical practice, in conjunction with assessment of in vivo IFN- $\beta$ bioactivity by measuring $M x A$ gene expression (Farrell and Giovannoni 2010). In the RGA, an IFN-responsive cell line is transfected with a plasmid in which an IFN-inducible promoter controls the expression of an enzyme, for example, firefly luciferase or alkaline phosphatase, which is measured by simple addition of enzyme substrate, often within hours of IFN stimulation. Since the IFN-induced enzymatic activity is directly related to IFN concentration, the presence of NAbs inhibits the amount of enzyme produced (Lallemand and others 2008; Lam and others 2008). Using sensitive quantitative reverse transcription-polymerase chain reaction technology to determine the levels of specific IFN-induced mRNA, for example, $M x A$ mRNA or 6-16 mRNA provides assays that require a shorter period of stimulation with IFN- $\beta$ and can be completed within a day (Bertolotto and others 2007; Aarskog and others 2009; Moore and others 2009) in common with the RGA (Lallemand and others 2008). The potential for high throughput applications is increased if branched DNA 
technology is used, as gene expression is measured without the requirement for RNA extraction and cDNA synthesis (Moore and others 2009). However, if different methods are used, it is possible that noncomparable results will be produced. By validating such new procedures or indeed older procedures for example, CPE assays against the standardized assay described here, such inconsistencies should be avoided. The data in Fig. 2 of our study have clearly demonstrated that the NAb assay can be successfully transferred to an independent laboratory for cross-validation studies with an in-house assay. Furthermore, a high correlation was noted between the MxA protein assay and the RGA used in the study.

Use of the standardized NAb assay will enable compliance with the EMA statement "it should be stressed that in case the sponsors use (those) new technologies, they will have to demonstrate how the new assay compares to the agreed upon common assay, so as to guarantee standardisation in the expression of the results in antibody formation and incidence rate" (EMA, 2008).

\section{Acknowledgments}

The authors thank the study participants for their valuable contribution and support with the study. They also thank Novartis Pharmaceuticals Corporation for provision of the MxA hybridomas, Biogen Idec for MxA antibodies; Axel Olivar (Bayer Pharma AG) and Gordon Francis (Novartis Pharmaceuticals Corporation) for a critical review of this article; and Patsy McCarthy and Morten Svenson (Biomonitor Ltd) and Anthony Meager (NIBSC) for their assistance. They are especially grateful to Rose Gaines Das (NIBSC) for a statistical analysis of the data. They also extend their thanks to the Biologics Working Party and Secretariat of the EMA for their assistance and support throughout this study.

\section{Author Disclosure Statement}

No competing financial interests exist.

\section{References}

Aarskog N, Marøy T, Myhr K, Vedeler C. 2009. Antibodies against interferon-beta in multiple sclerosis. J Neuroimmunol 212:148-150.

Bertolotto A. 2009. Implications of neutralising antibodies on therapeutic efficacy. J Neurol Sci 277 Suppl 1:S29-S32.

Bertolotto A, Deisenhammer F, Gallo P, Sölberg Sørensen P. 2004. Immunogenicity of interferon beta: differences among products. J Neurol 251 Suppl 2:II15-II24.

Bertolotto A, Gilli F, Sala A, Capobianco M, Malucchi S, Milano E, Melis F, Marnetto F, Lindberg RL, Bottero R, Di Sapio A, Giordana MT. 2003. Persistent neutralizing antibodies abolish the interferon beta bioavailability in MS patients. Neurology 60:634-639.

Bertolotto A, Sala A, Caldano M, Capobianco M, Malucchi S, and others. 2007. Development and validation of a real time PCRbased bioassay for quantification of neutralizing antibodies against human interferon-beta. J Immunol Methods 321:19-31.

Clerico M, Contessa G, Durelli L. 2007. Interferon-beta1-a for the treatment of multiple sclerosis. Expert Opin Biol Ther 7: 535-542.

Comi G, De Stefano N, Freedman MS, Barkhof F, Polman CH, Uitdehaag BM, Casset-Semanaz F, Hennessy B, Moraga MS, Rocak S, Stubinski B, Kappos L. 2012. Comparison of two dosing frequencies of subcutaneous interferon beta-1a in pa- tients with a first clinical demyelinating event suggestive of multiple sclerosis (REFLEX): a phase 3 randomised controlled trial. Lancet Neurol 11(1):33-41.

Deisenhammer F. 2009. Neutralizing antibodies to interferonbeta and other immunological treatments for multiple sclerosis: prevalence and impact on outcomes. CNS Drugs 23:379-396.

Dhib-Jalbut S, Marks S. 2010. Interferon-beta mechanisms of action in multiple sclerosis. Neurology 74 Suppl 1:S17-S24.

Durelli L, Verdun E, Barbero P, Bergui M, Versino E, Ghezzi A, Montanari E, Zaffaroni M; Independent Comparison of Interferon (INCOMIN) Trial Study Group. 2002. Every-otherday interferon beta-1b versus once-weekly interferon beta-1a for multiple sclerosis: results of a 2-year prospective randomised multicentre study (INCOMIN). Lancet 359(9316):1453-1460.

European Medicines Agency (EMA). 2007. Guideline on immunogenicity assessment of biotechnology-derived therapeutic proteins. Available at www.emea.europa.eu/pdfs/ human/biosimilar/1432706en.pdf

European Medicines Agency (EMA). 2008. Beta-interferons and neutralising antibodies (in multiple sclerosis), EMEA/ CHMP/BWP/580136/2007. Available at www.ema.europa .eu/docs/en_GB/document_library / Report/2009/11/ WC500015395.pdf

Farrell RA, Espasandin M, Lakdawala N, Creeke PI, Worthington V, Giovannoni G. 2011. Incorporation of an interferon- $\beta$ neutralizing antibody assay into routine clinical practice. Mult Scler 17(11):1333-1340.

Farrell RA, Giovannoni G. 2010. Current and future role of interferon beta in the therapy of multiple sclerosis. J Interferon Cytokine Res 30(10):715-726.

Files JG, Gray JL, Do LT, Foley WP, Gabe JD, Nestaas E, Pungor E, Jr. 1998. A novel sensitive and selective bioassay for human type I interferons. J Interferon Cytokine Res 18(12):1019-1024.

Files JG, Hargrove D, Delute L, Cantillon M. 2007. Measured neutralizing titres of IFN-beta neutralizing antibodies (NAbs) can depend on the preparations of IFN-beta used in the assay. J Interferon Cytokine Res 27(8):637-642.

Francis GS, Rice GP, Alsop JC; PRISMS Study Group. 2005. Interferon beta-1a in MS: results following development of neutralizing antibodies in PRISMS. Neurology 65(1):48-55.

Giovannoni G. 2012. The REFLEX study: a missed opportunity? Lancet Neurol 11(1):22-24.

Gneiss C, Koudouovoh-Tripp PM, Ropele S, Gotwald T, Ehling R, Lutterotti A, Aichner F, Ladurner G, Eggers C, Schautzer F, Künz B, Millonig A, Aspeck E, Reindl M, Berger T, Fazekas F, Deisenhammer F. 2009. Influence of interferon-beta therapy switching on neutralizing antibody titres: results from the Austrian Switch Study (ASS). Mult Scler 15:1481-1488.

Goodin DS. 2005. Treatment of multiple sclerosis with human beta interferon. Int MS J 12:96-108.

Goodin DS, Hartung HP, O'Connor P, Filippi M, Arnason B, Comi G, Cook S, Jeffery D, Kappos L, Bogumil T, Knappertz V, Sandbrink R, Beckmann K, White R, Petkau J, Pohl C; BEYOND Study Group. 2012. Neutralizing antibodies to interferon beta-1b multiple sclerosis: a clinico-radiographic paradox in the BEYOND trial. Mult Scler 18(2):181-195.

Goodin DS, Hurwitz B, Noronha A. 2007. Neutralizing antibodies to interferon beta- $1 \mathrm{~b}$ are not associated with disease worsening in multiple sclerosis. J Int Med Res 35(2):173-187.

Grossberg SE, Kawade Y, Kohase M, Klein JP. 2001a. The neutralization of interferons by antibody. II. Neutralizing antibody unitage and its relationship to bioassay sensitivity: the tenfold reduction unit. J Interferon Cytokine Res 21:743-755.

Grossberg SE, Kawade Y, Kohase M, Yokoyama H, Finter N. 2001b. The neutralization of interferons by antibody. I. 
Quantitative and theoretical analyses of the neutralization reaction in different bioassay systems. J Interferon and Cytokine Res 21:729-742.

Hartung HP, Polman C, Bertolotto A, Deisenhammer F, Giovannoni G, and others. 2007. Neutralizing antibodies to interferon beta in multiple sclerosis: expert panel report. J Neurol 254:827-837.

Jacobs LD, Cookfair DL, Rudick RA, Herndon RM, Richert JR, Salazar AM, Fischer JS, Goodkin DE, Granger CV, Simon JH, Alam JJ, Bartoszak DM, Bourdette DN, Braiman J, Brownscheidle CM, Coats ME, Cohan SL, Dougherty DS, Kinkel RP, Mass MK, Munschauer FE, 3rd, Priore RL, Pullicino PM, Scherokman BJ, Whitham RH, and others. 1996. Intramuscular interferon beta-1a for disease progression in relapsing multiple sclerosis. Ann Neurol 39:285-294.

Kappos L, Clanet M, Sandberg-Wollheim M, Radue EW, Hartung HP, Hohlfeld R, Xu J, Bennett D, Sandrock A, Goelz S. 2005. European Interferon Beta-1a IM Dose-Comparison Study Investigators.Neutralizing antibodies and efficacy of interferon beta-1a: a 4-year controlled study. Neurology 65(1):40-47.

Karpusas M, Whitty A, Runkel L, Hochman P. 1998. The structure of human interferon-beta: implications for activity. Cell Mol Life Sci 54:1203-1216.

Kawade Y. 1986. Quantitation of neutralization of interferon by antibodies. Methods Enzymol 119:558-573.

Killestein J, Rudick RA, Polman CH. 2011. Oral treatment for multiple sclerosis. Lancet Neurol 10(11):1026-1034.

Koch-Henriksen N, Sorensen PS, Bendtzen K, Flachs EM. 2009. The clinical effect of neutralizing antibodies against interferon-beta is independent of the type of interferon-beta used for patients with relapsing-remitting multiple sclerosis. Mult Scler 15:601-605.

Lallemand C, Meritet JF, Erickson R, Grossberg SE, Roullet E, and others 2008. Quantification of neutralizing antibodies to human type I interferons using division-arrested frozen cells carrying an interferon-regulated reporter-gene. J Interferon Cytokine Res 28:393-404.

Lam R, Farrell R, Aziz T, Gibbs E, Giovannoni G, Grossberg S, Oger J. 2008. Validating parameters of a luciferase reporter gene assay to measure neutralizing antibodies to IFN beta in multiple sclerosis patients. J Immunol Methods 336:113-118.

Li DK, Paty DW. 1999. Magnetic resonance imaging results of the PRISMS trial: a randomized, double-blind, placebocontrolled study of interferon-beta1a in relapsing-remitting multiple sclerosis. Prevention of Relapses and Disability by Interferon-beta1a Subcutaneously in Multiple Sclerosis. Ann Neurol 46(2):197-206.

Lublin FD, Reingold SC. 1996. Defining the clinical course of multiple sclerosis: results of an international survey. Neurology 46:907-911.

McKay F, Schibeci S, Heard R, Stewart G, Booth D. 2006. Analysis of neutralizing antibodies to therapeutic interferon-beta in multiple sclerosis patients: a comparison of three methods in a large Australian cohort. J Immunol Methods 310:20-29.

Meager A, Gaines Das R. 2005. Biological standardization of human interferon beta: establishment of a replacement world health organization international biological standard for human glycosylated interferon beta. J Immunol Methods 306:1-15.

Moore M, Meager A, Wadhwa M, Burns C. 2009. Measurement of neutralizing antibodies to type I interferons by gene expression assays specific for type 1 interferon-inducible 6-16 mRNA. J Pharm Biomed Anal 49:534-539.
Pachner AR, Cadavid D, Wolansky L, Skurnick J. 2009. Effect of anti-IFN \{beta\} antibodies on MRI lesions of MS patients in the BECOME study. Neurology 73:1485-1492.

Polman $\mathrm{CH}$, Bertolotto A, Deisenhammer F, Giovannoni G, Hartung HP, Hemmer B, Killestein J, McFarland HF, Oger J, Pachner AR, Petkau J, Reder AT, Reingold SC, Schellekens H, Sørensen PS. 2010. Recommendations for clinical use of data on neutralising antibodies to interferon-beta therapy in multiple sclerosis. Lancet Neurol 9(7):740-750.

PRISMS (Prevention of Relapses and Disability for Interferon beta-1a subcutaneously in Multiple Sclerosis) Study Group. 1998. Randomised double-blind placebo-controlled study of interferon beta-1a in relapsing multiple sclerosis. Lancet 352:1498-1504.

Pungor E, Jr., Files JG, Gabe JD, Do LT, Foley WP, and others. 1998. A novel bioassay for the determination of neutralizing antibodies to IFN $\beta 1$. J Interferon Cytokine Res 18:10251030.

Rio J, Porcel J, Tellez N, and others. 2005. Factors related with treatment adherence to interferon beta and glatiramer acetate therapy in multiple sclerosis. Mult Scler 11:306-309.

Rudick RA, Goelz SE. 2011. Beta-interferon for multiple sclerosis. Exp Cell Res 317(9):1301-1311.

Runkel L, Meier W, Pepinsky RB, Karpusas M, Whitty A, Kimball K, Brickelmaier M, Muldowney C, Jones W, Goelz SE. 1998. Structural and functional differences between glycosylated and non-glycosylated forms of human interferon- $\beta$ (IFN- $\beta$ ). Pharm Res 15:641-649.

Scagnolari C, Duda P, Bagnato F, De Vito G, Alberelli A, Lavolpe V, Girardi E, Durastanti V, Trojano M, Kappos L, Antonelli G. 2007. Pharmacodynamics of interferon beta in multiple sclerosis patients with or without serum neutralizing antibodies. J Neurol 254:597-604.

Sominanda A, Rot U, Suoniemi M, Deisenhammer F, Hillert J, Fogdell-Hahn A. 2007. Interferon beta preparations for the treatment of multiple sclerosis patients differ in neutralizing antibody seroprevalence and immunogenicity. Mult Scler 13:208-214.

Towbin H, Schmitz A, Jakschies D, Von Wussow P, Horisberger MA. 1992. A whole blood immunoassay for the interferoninducible human Mx protein. J Interferon Res 12(2):67-74.

van Beers MM, Sauerborn M, Gilli F, Hermeling S, Brinks V, Schellekens H, Jiskoot W. 2010. Hybrid transgenic immune tolerant mouse model for assessing the breaking of B cell tolerance by human interferon beta. J Immunol Methods 352(1-2):32-37.

Address correspondence to: Dr. Meenu Wadhwa Biotherapeutics Group National Institute for Biological Standards and Control Blanche Lane South Mimms Potters Bar Hertfordshire, EN6 3QG United Kingdom

E-mail: meenu.wadhwa@nibsc.org

Received 27 July 2012/Accepted 7 April 2013 